\title{
Intradialytic Muscle Cramp and its Association with Peripheral Arterial Disease in End Stage Renal Disease Patients on Hemodialysis
}

\author{
Madhav Ghimire, ${ }^{1}$ Sanjib Kumar Sharma, ${ }^{2}$ Romila Chimoriya, ${ }^{3}$ Gopal Chandra Das ${ }^{1}$ \\ 'Department of Nephrology, ${ }^{2}$ Department of Cardiology, College of Medical Sciences Teaching Hospital, Chitwan, Nepal \\ ${ }^{3}$ Department of Pediatrics, Nobel Medical College Teaching Hospital, Biratnagar, Nepal
}

Introduction: Muscle cramp is a common intradialytic complication observed in hemodialysis patients. Similarly Peripheral arterial disease is a common condition in the hemodialysis population. No study on intradialytic muscle cramp and its association with Peripheral arterial disease is yet reported from Nepal.
\end{abstract}

Methods: Fifty patients with a diagnosis of End Stage Renal Disease who were on hemodialysis were studied over a period of one year. Muscle cramp was defined clinically as contractions of a large muscle group and Peripheral arterial disease was diagnosed on the basis of the ankle -brachial index (ABI). Chi square $\left(\mathrm{X}^{2}\right)$ test was used to determine the association between Intradialytic Muscle cramps and Peripheral Arterial Disease (PAD).

Results: A total of 50 End Stage Renal Disease patients were analyzed. The mean age of the patient was $49.81 \pm 12.63$ years. The major causes of End Stage Renal Disease in the study population was Chronic Glomerulonephritis $40 \%(n=20)$. Muscle cramps were present in $26 \%(n=13)$ cases. Peripheral arterial disease was present in $30 \%(n=15)$ of patients. However there was no statistically significant association between the presence of Intradialytic Muscle cramps and peripheral arterial disease $(\mathrm{p}$ value $=0.18)$

Conclusions: Intradialytic Muscle cramps and peripheral arterial disease were common occurrence in end stage renal disease patients on hemodialysis patients, however there was no association between the presence of intradialytic Muscle cramps and peripheral arterial disease.

Keywords: end stage renal disease; intradialytic muscle cramps; peripheral arterial disease.

\section{INTRODUCTION}

Chronic kidney disease (CKD) is a major public health problem in Nepal. It is estimated that the prevalence of CKD is around $10.6 \%$ in urban areas of Nepal and the three most common causes of End Stage Renal Disease (ESRD) in Nepal are believed to be Diabetes Mellitus, Glomerulonephritis and Hypertension. ${ }^{1}$ Majority of people with ESRD need renal replacement therapy and hemodialysis is the most popular and widely used renal replacement therapy, worldwide. In Nepal, Hemodialysis service was first started in Bir Hospital in $1987^{2}$ and in our center it was started in 2007. All ESRD patients in

Correspondence: Dr. Madhav Ghimire, Department of Nephrology, College of Medical Sciences Teaching Hospital, Bharatpur, Chitwan, Nepal. E-mail: madhavghimirenp@yahoo.com, Phone : +977. 98550-60179. 
our center are in hemodialysis programme. Over the last 40 years, hemodialysis (HD) technology has undergone a great transformation in its form and treatment. Once used as a specialized treatment to a selected privileged population in university based hospitals has now become a routine outpatient treatment. This change in practice has been because of the technological advances and reliability of dialysis machine equipment, vascular access, dialyzer membranes, and water supply system. However, adverse events do still occur during dialysis, which may be because of technical problems with the extracorporeal treatment, often combined with underlying patient co-morbidity. Muscle Cramps is a common intradialytic complication observed in hemodialysis patients with an estimated prevalence ranging from 33 to $86 \%$ cases. $^{3}$

\begin{tabular}{|lrc|}
\hline \multicolumn{3}{|c|}{ Table 1. Causes of ESRD in the Hemodialysis Cohort. } \\
\hline \multicolumn{1}{|c|}{ Cause of ESRD } & Number & Percentage \\
Chronic & 20 & $40 \%$ \\
Glomerulonephritis & 14 & $28 \%$ \\
Type 2 DM & 12 & $24 \%$ \\
HTN & 2 & $4 \%$ \\
Sepsis(ATN) & \\
\hline
\end{tabular}

Peripheral Arterial Disease (PAD) is a common problem in Chronic Kidney Disease. Moreover, its prevalence is seen to be much higher among hemodialysis patients than in the general population with an estimated prevalence ranging from $17 \%$ and $48 \% .^{4,5}$ Knowledge of the PAD in patients with CKD (Chronic Kidney Disease) is limited because of a lack of routine evaluation and detection. The prevalence of PAD appears to be higher among ESRD (End Stage Renal Disease) patients than in the general population due to dialysis or uremiaassociated risk factors. ${ }^{4}$ However less is known about the prevalence of Intradialytic Muscle cramps and its association with PAD in chronically hemodialyzed patients. Previously in one study 6 the association of Peripheral arterial disease and Muscle cramp was studied in hemodialysis population. However the result was negative suggesting no association.

This study was carried out with an objective to assess the prevalence of Intradialytic Muscle cramps in End Stage Renal Disease (ESRD) and its association with PVD.

\section{METHODS}

This hospital based cross sectional study was carried out at Hemodialysis Unit of College of Medical Sciences Teaching hospital over a period of one year; from October 2010 to September 2011, where 50 cases of hemodialysis patients were prospectively analyzed.

\begin{tabular}{|c|c|c|c|c|c|c|c|}
\hline S.N & Age ( yrs) & Sex & Cause & Comorbidity & $\begin{array}{l}\text { Duration of HD (In } \\
\text { Months) }\end{array}$ & $\begin{array}{l}\text { Body Mass } \\
\text { Index }\end{array}$ & $A B I$ \\
\hline 1. & 45 & $\mathrm{M}$ & HTN & HTN & 9 & 18.75 & $\geq 0.9$ \\
\hline 2. & 57 & M & T2 DM & $\begin{array}{c}\text { HTN/ } \\
\text { HYPOTHYROIDISM }\end{array}$ & 12 & 23.3 & $\geq 0.9$ \\
\hline 3. & 24 & $\mathrm{~F}$ & CGN & $\mathrm{HTN} / \mathrm{CCF}$ & 10 & 17.7 & $\geq 0.9$ \\
\hline 4. & 59 & $\mathrm{~F}$ & T2 DM & $\mathrm{HTN} / \mathrm{CCF}$ & 24 & 20.7 & $\leq 0.9$ \\
\hline 5. & 27 & M & SEPSIS & HTN & 8 & 29.5 & \\
\hline 6. & 65 & $\mathrm{~F}$ & HTN & HTN/COAD & 12 & 25.2 & $\leq 0.9$ \\
\hline 7. & 42 & M & CGN & HTN & 6 & 25.3 & $\geq 0.9$ \\
\hline 8. & 27 & M & CGN & HTN & 6 & 27 & $\geq 0.9$ \\
\hline 9. & 18 & M & CGN & HTN & 4 & 26.6 & $\geq 0.9$ \\
\hline 10. & 35 & $\mathrm{~F}$ & CGN & HTN & 8 & 19.5 & $\geq 0.9$ \\
\hline 11. & 32 & M & CGN & HTN & 24 & 18.7 & $\geq 0.9$ \\
\hline 12. & 36 & $\mathrm{~F}$ & CGN & HTN & 9 & 18 & $\geq 0.9$ \\
\hline 13. & 38 & $\mathrm{~F}$ & CGN & HTN & 6 & 19.4 & $\geq 0.9$ \\
\hline
\end{tabular}

Inclusion criteria

1. Patients with an established diagnosis of ESRD, irrespective of the underlying etiology. (ESRD was defined when there was irreversible loss in GFR $\leq 5 \mathrm{ml} /$ min. ${ }^{7,8}$ Cock-Croft and Gault Equation used)
2. Patients on Hemodialysis for more than 3 months.

3. Patient giving informed written consent. 
Ghimire et al. Intradialytic Muscle Cramp and its Association with Peripheral Arterial Disease in End Stage Renal Disease...

\section{Exclusion criteria}

1. Patient with documented diagnosis of Peripheral Arterial calcification.

2. Patient with bilateral arteriovenous fistula.

3. Patient with Non-compressible upper and or lower limb vessels.

- Non Compressible vessel (Defined as) ${ }^{6}$

An $\mathrm{ABI}>1.30$ or

- An apparent lower extremity systolic pressure above $300 \mathrm{mmHg}$ defined the presence of a noncompressible vessel.

4. Patient with Intradialytic hypotension (Defined as) ${ }^{9}$

- Decrease in systolic BP $\geq 20 \mathrm{mmHg}$ or

- Decrease in mean arterial pressure (MAP) by $10 \mathrm{mmHg}$ associated with clinical events and need for nursing interventions

5. Patient with electrolyte imbalance

- Hypocalcaemia, Hyperkalemia, Hyponatremia, Hypernatremia, Hypokalemia, Hypomagnesaemia.

6. Patient with prior history of Muscle cramp before starting Hemodialysis

Intradialytic Muscle cramp was defined as contractions of a large muscle group sufficiently painful that required treatment and or change in dialysis orders for the purpose of averting muscle cramps. ${ }^{7}$ and Peripheral arterial disease was considered positive when $A B I$ $\leq 0.9 .{ }^{10}$ The highest systolic blood pressure in Posterior tibial artery or dorsalis pedis artery (whichever was high) was taken and then divided by the systolic blood pressure in the brachial artery from the upper limb to calculate the ABI. An ultrasound Doppler was used to document the Peripheral arterial disease. Data was carefully entered on MS XP sheet and then the data was converted to SPSS PC +16 version for statistical analysis. Chi square (X2) test was used to examine the association between Intradialytic Muscle cramps and PAD. Ratio, mean and standard deviation were calculated for descriptive data.

\section{RESULTS}

A total of 50 End Stage Renal Disease patients were analyzed. The mean age of the patient was $49.81 \pm 12.63$ years. The age range was from $18-79$ years. Majority of them were Males $64 \%(n=32)$. The three major causes of CKD (ESRD) in the study population on hemodialysis were Chronic Glomerulonephritis 40 $\%(n=20)$ followed by Type 2 DM $28 \%(n=14)$ and Hypertension $24 \%(n=12)$.

Muscle cramps defined as contractions of a large muscle group sufficiently painful that the patient required relief with medication or termination of dialysis session was present in $26 \%(n=13)$ cases. The mean age of the patient who experienced the muscle cramp was $38.84 \pm 11.34$ years. Majority of the people to experience the muscle cramps were male $(n=8)$. Majority of them were having $\operatorname{CGN}(n=8)$ as their underlying diagnosis of ESRD.

Peripheral vascular disease defined by $A B I \leq 0.9$ was present in $30 \%(n=15)$ of patients and the intradialytic muscle cramps was seen in $(n=2)$ of cases with PVD. However there was no statistically significant association between the presence of Intradialytic Muscle cramp and PAD ( $p$ value $=0.18$ ). Out of 13 cases with Muscle cramp, PAD was present in $(n=2)$ cases. Both Intradialytic Muscle Cramp and PAD was present $(n=2)$ cases. On statistical analysis intradialytic muscle cramp was not significantly associated with $\operatorname{PAD}(\mathrm{ABI} \leq 0.9)$.

\begin{tabular}{|c|c|}
\hline \multicolumn{2}{|c|}{ Variables $\quad$ PVD Present $(A B I \leq 0.9)$} \\
\hline PVD Absent $(A B I \geq 0.9)$ & $\mathrm{p}$ Value \\
\hline \multicolumn{2}{|c|}{ Symptom of Muscle 2} \\
\hline 11 & 0.18 \\
\hline $\begin{array}{l}\text { Cramps during } \\
\text { hemodialysis }\end{array}$ & \\
\hline
\end{tabular}

\section{DISCUSSION}

Muscle cramp is the second most common reported intradialytic complication associated with HD after hypotension. It can occur in as many as $20 \%$ of dialysis treatments. Although its pathogenesis is unclear, cramps are known to be more frequent when UF rates are high, during episodes of hypotension, and when dialysate with low sodium concentration is used, an indication that cramps are caused by acute extracellular volume contraction. ${ }^{11}$ Muscle cramp is a common complication of hemodialysis treatment, occurring in 33 to 86 percent of patients ${ }^{3}$. In our study we also observed a prevalence of $26 \%(n=13)$ of muscle cramps. Majority of the patients who developed muscle cramps in our study were male and the cause of ESRD in them was Chronic Glomerulonephritis $(n=8)$. However none of the study have shown the association of muscle cramps with the sex and the cause of ESRD. In a review of computerized records of 22,514 dialysis performed in 531 patients at five different outpatients dialysis units, an average of $12 \%$ of treatments were complicated by cramps, whereas the cumulative incidence over a five months interval was $66 \% .{ }^{12}$ In a hospital based study done in Nepal Medical College by Chhetri et al, among 33 ESRD patients who were undergoing hemodialysis, $25 \%$ patients developed 
muscle cramps. ${ }^{13}$ In a study by Cheryl et al ${ }^{14}$ it was seen that out of Thirty-six patients who agreed to participate, only 12 experienced cramps. Four subjects had only one recorded episode, four subjects had two recorded episodes, and one subject each had $3,4,5$, and 9 recorded episodes.

In another study conducted by Pandero et al, ${ }^{15}$ muscle cramps occurred in $26 \%$ of the patients. Yet in another study $^{16}$ intradialytic cramps were seen to develop repeatedly in about $25 \%$ of all hemodialysis patients. Such cramps tend to occur most frequently near the end of hemodialysis treatments and the changes in plasma osmolality and/or extracellular fluid volume have been implicated for that. Cramps occurring during the dialysis treatment most commonly involve the muscles of the lower extremity, namely gastrocnemius and other small muscles of foot ${ }^{17}$ but the muscles of the hands, arms, and abdomen may also be affected ${ }^{3}$. Cramps tend to occur late in the dialysis and more common in the age group of $30-50$ years. ${ }^{12} \mathrm{We}$ also noticed that the muscle cramps were experienced near the end of the hemodialysis treatment. In relation to the time on hemodialysis, most patients in our study group developed muscle cramps in between 6- 12 months of hemodialysis $(n=9)$. Cramps occur more often in older, nondiabetic, anxious patients. ${ }^{3},{ }^{17}$ However our patients who developed muscle cramps were young ( $\leq 50$ years) ( $n=10$ ) but they majority of them were nondiabetic $(n=11)$. Low PTH values is also frequently seen among patients with dialysis-associated cramps. ${ }^{18 .}$ However no such association was seen in our study.

The exact etiology of cramps in dialysis patients is unknown. The etiology of hemodialysis-associated cramps may be related to one or more of the following factors: (1) Plasma volume contraction (2) Hyponatremia (3) Tissue hypoxia (4) Hypomagnesaemia (5) Carnitine deficiency and (6) Elevated serum leptin levels. ${ }^{3,17}$ Of these, volume contraction and hyponatremia, either alone or in combination, are the most likely underlying causative factors.

Peripheral arterial disease (PAD) has been suggested as a causative factor to the development of intradialytic muscle cramps in patients on maintenance hemodialysis. Recently Michener et al ${ }^{19}$ suggested that patients with PAD may be predisposed to intradialytic cramps resulting from the incremental hemodynamic compromise associated with volume removal during dialysis. Supporting this hypothesis, they demonstrated decreases in peripheral hemoglobin oxygen saturation in the leg of post dialysis patients with PAD. ${ }^{19}$

In another study done by Caplin et al, ${ }^{20}$ intradialytic muscle cramps was seen in $74.3 \%$ and the patients with PAD were more prone to develop cramps. However, on multivariate analysis, PAD was not independently associated with intradialytic symptoms. In our study, we also tried to show the association of muscle cramps with PAD. We found that, in total the muscle cramps developed in $26 \%(n=13)$ cases however in PVD group, muscle cramps developed in $13.3 \%(n=2)$ cases. In statistical analysis there was no significant association of muscle cramps with PVD ( $p$ value $=0.18$ ).

Similar to our study, a study conducted by Brass et al ${ }^{6}$ also showed that PVD was common in hemodialysis patients, but there was no association between the presence of PAD and the prevalence of intradialytic muscle cramps.

We tried to exclude all the possible causes of muscle cramps other than PVD. Such as the intradialytic hypotension, electrolyte imbalance and the past history of muscle cramp before the initiation of hemodislysis and in the first 3 month of hemodialysis. However we couldn't do the serum carnitine level and serum leptin level which are possible cause of muscle cramps in the hemodialysis patients. So their effect on the intradialytic muscle cramps could not be excluded. This might have confounded the effect of PVD on muscle cramps. This is one of the limitation of our study.

\section{CONCLUSIONS}

This study demonstrated that the prevalence of both intradialytic muscle cramp and peripheral arterial disease were high. However there was no association of intradialytic muscle cramp with the Peripheral arterial disease.

\section{REFERENCES}

1. Sharma SK, Karki P, Baral N, Perico N, Perna A, Remuzzi $G$, et al. A community screening for chronic kidney disease, hypertension, diabetes and their management in Dharan, Nepal. World Congress of Nephrology, Rio de Janeiro, Brazil, 21-25 April, 2007, 415.
2. Chhetri PK, Satyal PR, Kafle R, Khakurel S, Pradhan BR. Experience of hemodialysis in Bir Hospital. Nepal Med Coll J 1999; 1: 99-101 
3. Canzanello, VJ, Burkart, JM. Hemodialysis-associated muscle cramps. Semin Dial 1992; 5:299. ) and is an important cause of early termination of dialysis sessions. ${ }^{4}$ (Rocco MV, Burkart JM. Prevalence of missed treatments and early sign-offs in hemodialysis patients. J Am Soc Nephrol 1993; 4:1178-83.

4. O'Hare AM, Johansen KL. Lower-extremity peripheral arterial disease among patients with end-stage renal disease. J Am Soc Nephrol 2001; 12: 2838-47.

5. O'Hare AM, Hsu CY, Bacchetti P, Johansen KL. Peripheral vascular disease risk factors among patients undergoing hemodialysis. J Am Soc Nephrol 2002; 13: 497-503.

6. Brass EP, Adler S, Sietsema KE, Amato A, Esler A, Hiatt WR. Peripheral Arterial Disease Is Not Associated with an Increased Prevalence of Intradialytic Cramps in Patients on Maintenance Hemodialysis. Am J Nephrol 2002; 22:491-6.

7. National Kidney Foundation. K/DOQI clinical practice guidelines for chronic kidney disease: evaluation, classification, and stratification. Am J Kidney Dis 2002; 39:S1.

8. Levey AS, Eckardt KU, Tsukamoto Y, Levin A, Coresh $\mathrm{J}$, Rossert J, et al. Definition and classification of chronic kidney disease: a position statement from kidney disease: Improving global outcomes (KIDIGO). Kidney Int'l 2005; 67(6): 2089-100.

9. K/DOQI Clinical Practice Guidelines for Cardiovascular Disease in Dialysis Patients. Am J Kidney Dis. 2005; 45 (4 Suppl 3):S1-153

10. Ono K, Tsuchida A, Kawai H, Matsuo H, Wakamatsu R, Maezawa A, et al. Ankle $\square$ brachial blood pressure index predicts all $\square$ cause and cardiovascular mortality in hemodialysis patients. J. Am. Soc. Nephrol 2003; 14 (6):1591-8.

11. Jonathan H, Peale C, Gerald S. Hemodialysis. In: Brenner Barry M and Levine Samuel A, editors. Brenner and Rector`s The Kidney 8th ed. Philadelphia, Saunders, Elsevier; 2008.
12. Levin NW, Kupin WL, Zasuwa G, Venkat KK, Norwalk CT. Complications during hemodialysis. In: Nissensson AR, Fine RN, Gentile DE, editors. Clinical dialysis. 2nd ed. Norwalk, Conn; Applenton \& Lange1990.)

13. Chhetri PK, Manandhar DN, Tiwari R, Lamichhane S. In center hemodialysis for end stage kidney disease at Nepal Medical College and Teaching Hospital. Nepal Med Coll J.2009; 11(1):61-3.

14. Cheryl RN, Resnikoff E, Allan MU. Treatment of Dialysis-Related Muscle Cramps with Hypertonic Dextrose. Arch Intern Med 1981; 141:171-173.

15. Panadero Sandoval J, Pérez García A, Martin Abad L, Piqueras A, Garcés L, Chacón JC, Cruz JM. Action of quinine sulphate on the incidence of muscle cramps during hemodialysis. Med Clin (Barc). 1980; 75(6):247-9.

16. Chou CT, Wasserstein A, Schumacher HJ, Fernandez P. Musculoskeletal manifestations in hemodialysis patients. J Rheumatol 1985; 12(6): 1149-53.)

17. McGee SR. Muscle cramps. Arch Intern Med 1990; 150:511.

18. Noordzij M, Boeschoten EW, Bos WJ, Dekker FW, Bossuyt PM, Krediet RT, Korevaar JC. Disturbed mineral metabolism is associated with muscle and skin complaints in a prospective cohort of dialysis patients. Nephrol Dial Transplant 2007; 22:2944.

19. Michener B, Levi M, Choudhury D. Dialysis volume removal may result in lower extremity ischemia. J Am Soc Nephrol 1998; 9(suppl):261A.

20. Caplin B, Kumar S, Davenport A. Patient's perspective of hemodialysis associated symptoms. Nephrol Dial Transplant 2011; 26: 2656-63. 